\title{
Coordinating chemists for global development
}

\author{
Chemistry research and education face challenges anywhere in the world, but more so in less developed - \\ or less stable - economies. These countries and their more economically fortunate neighbours can all \\ contribute to the development of chemistry and its ability to tackle local and global issues.
}

Chemistry has an important part to play when it comes to addressing some of the world's most pressing societal issues, including water and food security, better health, and cleaner energy. Unfortunately, in countries for which these problems are most acute, teaching chemistry and conducting chemical research are typically difficult to achieve effectively. Many regions of the developing world suffer from a lack of appropriate resources and this results in a variety of challenges - from insufficient funding to poor infrastructures to difficulties in accessing information that impede both research and education.

In this issue, a Commentary by Berhanu Abegaz (p. 518) and an Interview with Mauricio Erben (p. 523) explore the current situation of chemists in 'the South' - as less-developed countries are sometimes referred to, with the geographical north-south border roughly reflecting a socio-economic and political divide. Both articles emphasize that financial difficulties are not the only problem - and are often not even the main stumbling block to progress. Beyond money, they identify a variety of challenges faced by scientists in the developing world, as well as ways to overcome them and ultimately establish research and education systems that will no longer depend on help from wealthier countries.

In particular, Abegaz highlights the importance of improving education. Africa is a continent bursting with youth, potential and enthusiasm - but this means that teaching resources are being stretched very thin. This 'youth bulge' must be met with a merit-based education system that is able to accommodate increasing numbers of students and excite their interest, such as through hands-on experiments in programmes coordinated by skilled teachers. African chemistry can also draw on other assets, in particular its strong traditions in natural-products research and indigenous medicine, which can act as the basis for further growth in the field of drug discovery and development.

Different hurdles are faced by researchers in Argentina. Erben describes a country that benefits from a high-quality education system, yet in which research activities depend significantly on a volatile economic and political climate. He emphasizes the role

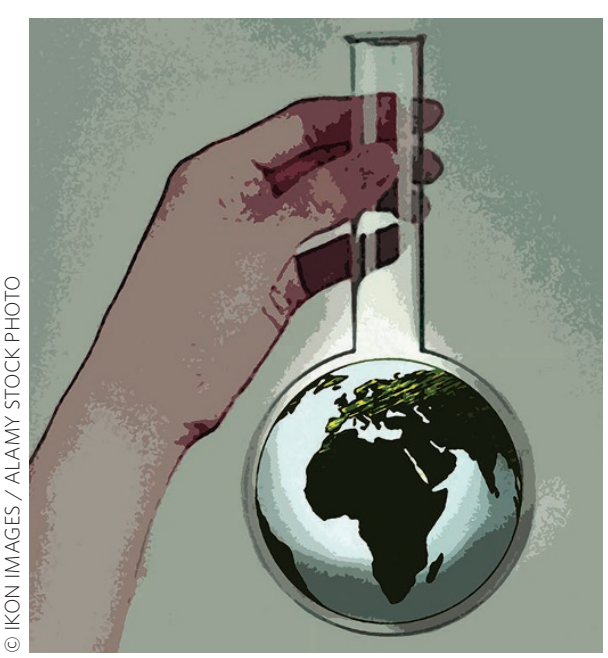

of policy-makers in the development of the country's science and technology system, and believes that bridging the gaps between the scientific community, the government and the public will help establish clear research directions and, in turn, lead to more rapid progress towards a set of agreed goals.

Common considerations emerge from these articles, such as the importance of focusing research and education activities on regional issues - for example the treatment of parasitic diseases - and of making better use of local resources, such as oil and metal supplies. Collaborations (South-South as well as South-North) are also identified as a key route to strengthening research. This point is a high priority of The World Academy of Sciences (TWAS). With a network of over 1,100 members, TWAS has been striving for over three decades to promote the advancement of scientific research and education in the developing world, with the aim of improving human well-being. It does this through supporting a range of activities - PhD or postdoctoral fellowships, research grants, meetings, prizes and awards, and visiting scientists - as well as through involvement in science policy, by providing decision-makers with scientific expertise.

These goals are also being pursued to different extents through other ventures. The Royal Society of Chemistry's pan-Africa network (http://go.nature.com/6qtzn7), for example, is also involved in encouraging collaborations between scientists, the support of teaching activities, and the communication of chemistry to wider society, while Nature travel grants (http://go.nature.com/IY51Jz) help delegates from developing countries to attend Gordon Research Conferences. At the level of individual interactions, an inspiring example is that of a chance meeting between chemists Martyn Poliakoff from the UK and Nigist Asfaw from Ethiopia that snowballed - "with modest funding and overseas support" - into the creation of a now-internationally recognized green chemistry research group in Addis Ababa University within only four years ${ }^{1}$.

All of these endeavours are important for the development of chemistry in the South. Financial assistance from developed countries is still required but diverse forms of training are also crucial - including collaborations, the hosting of students, and visiting professorships. Meanwhile, the talented and enthusiastic workforce of developing countries must be adequately engaged, trained and given a favourable environment to work in - with clear goals that are supported by governments. This workforce must also be carefully preserved. In a keynote lecture at the TWAS General Meeting in 2012, Nobel laureate Ahmed Zewail noted that "the developing world possesses very capable scientists and yet, unwittingly, continues to contribute outstanding scientists to the developed world as part of the brain-drain phenomenon"2, a point echoed in Erben's Interview.

Despite the undeniable challenges faced by chemists in some parts of the world, with the right assistance (financial and otherwise) the global chemistry community can grow. Anyone - no matter where they are - should be able to make valuable contributions to it and help tackle the important societal issues that chemistry can help to solve. Moreover, by increasing awareness of the particular problems faced in certain regions, a clear path to aiding the development of self-sustaining education and research programmes the whole world over may be within our grasp.

\section{References}

1. Asfaw, N., Licence, P., Engida, T. \& Poliakoff, M. Science 316, 1849-1850 (2007).

2. Zewail, A. H. Science in the developing world. TWAS Newsletter Vol. 14, 23-28 (TWAS, 2002); http://go.nature.com/DHKglx 